\title{
TERRITORIAL KNOWLEDGE ONTOLOGY AS A GUIDE FOR THE IDENTIFICATION OF RESOURCE OF THE TERRITORY TOWARD SUSTAINABILITY
}

\author{
Ezoji, Amer; Matta, Nada \\ University of Technology of Troyes
}

\begin{abstract}
Representation of territorial knowledge based on the ontology is an approach which explains the nature and reasoning of this knowledge for sustainability. This research proposes an ontology of domain according to the principles for modelling an ontology. This proposed ontology is named DOTK (descriptive ontology for territorial knowledge). DOTK ontology has specialized the entities of territorial knowledge for sustainability and its aim is enhancing the sustainable knowledge of actors within industries. This ontology is a guide for identifying an operational ontology of real example. This research show that ontology of domain can assist to the identifying of tangible and intangible resources of the local territory. So, these identified resources can help the industries and territory for sustainable objectives and improve the available territorial knowledge within local or regional industries.
\end{abstract}

Keywords: Ontologies, Sustainability, Knowledge management

\section{Contact:}

Ezoji, Amer

University of Technology of Troyes

Tech-cico

France

amer.ezoji@utt.fr 


\section{INTRODUCTION}

Sustainability issues affect every component of our society from individuals to regional and global organizations: major ecological or social crises are due to natural resource overconsumption and rising inequality at both local and global scales (Zahng et al., 2013). Concerning the growing role of sustainable development, it should foster better consideration of the sustainability aspect in the interaction between the industrial companies and territory for the specific goal. So, the growing attention to the sustainable development encourage the industries and companies to integrate the sustainability to their activities in different hierarchical levels from global strategic decisions by top management, through planning and organization by tactical management, to daily engineering and production activities of the operational area. Moreover, discovering of territorial resources can help the implementation of sustainability in industries. A territory is considered as value creation network for human where all of the intangible and tangible resources flow. Also, integration of tangible and intangible resources of territory (e.g. knowledge or materials) to industries activities can create economic and social value locally for sustainable objective (Allais et al., 2015). Also, the literature review is demonstrated which there is not enough knowledge about the territory's feature within industries and companies. So, it is a barrier to search possible concept for improving sustainable objective. Therefore, the emerged question is to identify the types of territorial knowledge which can assist the sustainable development within industries and companies. Moreover, the second question is that how this territorial knowledge can be represented for hierarchical levels. So, finding a method that can make explicit this knowledge for actors of the hierarchical level is necessary. An ontology is a useful tool that can share a common understanding of the structure of information and makes the domain assumption explicit (Fensel, 2001). So, in this paper, an ontology of territorial knowledge according to some principles is modelled to represent and analyse the interactions and effects of different influencing factors in local industries toward sustainability. So, for modelling an ontology of territorial knowledge, at the first step, the taxonomy of elements of territorial knowledge is done. Then, normalizing of these elements is done based on the foundational ontology of DOLCE (Descriptive Ontology for Linguistic and Cognitive Engineering). Finally, an ontology of domain is proposed which is named Descriptive Ontology for Territorial Knowledge (DOTK). The concepts of DOTK are identified base on the theoretical articles of territory for sustainability and this ontology justify the essence of elements of territorial knowledge according to the entities such as perdurants, endurans and abstract. Then, DOTK ontology is implemented in the real example for identifying knowledge in this real example. The aim of this implementation is to validate that DOTK ontology can act as a guide for modelling an operational ontology. Another goal is to prove that DOTK ontology can identify the tangible and intangible resources of each territory to represent these resources as knowledge for the hierarchical levels of the industry for the objective of sustainable development. Moreover, construction of DOTK ontology has this possibility to add other new elements of territorial knowledge for sustainable development which will be found by other researchers in future to complete the element of DOTK ontology.

\section{ONTOLOGY CONSTRUCTION}

The ontology is the heart of any knowledge description. Therefore, designing the ontology of a domain is a key issue for knowledge representation (Gruber, 1993). Designing an ontology corresponds to the conceptual modelling of categories of objects in a domain. Concepts must be elicited in the ontology and a commitment to their meaning is needed. This commitment has to take place at the knowledge level and it is tied up to the essence of objects. (Bouaud et al., 1995). So, it needs to derive some principles for justifying the structure of the ontology.

\subsection{Ontology}

An ontology is defined as a formal, explicit specification of a shared conceptualization. Basically, the role of ontologies is to facilitate the construction of a domain model (Hallstedt et al., 2010). Ontologies provide content theories about the sorts of objects, properties of objects, and relations between objects that are possible in a specified domain of knowledge (Fensel, 2000). Thus, the primary goal of ontologies is knowledge sharing for better communication, common understanding and it is possible with the explication of the context of ontology. 


\subsection{Principles for modelling an ontology}

The issue of knowledge representation is designing of formal representation system for the cognitive aspect of knowledge. To achieve this goal, a normalization of knowledge is a necessary step when the ontology of domain must be elicited (Bouaud et al., 1995). Moreover, designing an ontology corresponds to the conceptual modelling of categories of objects that are considered in a domain (Bachimont et al., 2002). An ontology is the result of modelling that focuses on the characterization of primitives for the formal representation of knowledge. So, the principles for modelling an ontology are explained.

\subsubsection{Fundamental issues of knowledge representation}

In non-formal domains, there are not complete definitions for the categories of objects by descriptive knowledge. So, Normalizing help the agreement of use of notions and it consists of an agreement on the meaning of domain by the manipulation of their explicit descriptions (Bouaud et al., 1995).

\subsubsection{Normalizing by necessary conditions}

A usual way of normalizing of the descriptive knowledge consists of the necessary relations between domain notions. The distinction between intension and extension is the necessary condition. The denotation of a type is its extension and objects characterized by the type. There is no explicit relation between the intension of a type, its meaning and its extension. So, the normalizing condition makes an explicit distance between the intentional definition of a type and its extension (Bouaud et al., 1995).

\subsubsection{Normalizing by necessary and sufficient conditions}

Taxonomies built from the necessary condition cannot allow the classification. The differences between a type and its genus are only necessary conditions for building a taxonomy and sufficient conditions need to the notion corresponds to the same knowledge (Bouaud et al., 1995). The knowledge normalization must be carried out in order to assign complete definitions of types. Also, normalizing by complete definitions is the essence of notions which are used their basic meaning (Bachimont, 2000).

\subsubsection{Characterizing the essential}

The essence of notions should be captured by assigning complete definitions of notions and their essential properties. So, building an ontology is to decide which object to retain the studied domain. The notion of object is intentional and corresponds to the ontology of the domain. Thus, defining types is by deciding the essential characteristics to build the ontology of the domain (Bachimont et al., 1991).

\subsubsection{Essence and taxonomy}

Types are defined in terms of necessary and sufficient conditions when the normalization process is completed. An essence is unique, and a type has a unique definition. Maybe the notion has two essences. So, there are two different sets of necessary and sufficient conditions to determine it. Therefore, these two definitions determine two different notions (Bouaud et al., 1995). A type consists of its properties. Moreover, the meaning of properties must be understood through its positions in the ontology. So, the same property in different positions does not have the same meaning (Bachimont et al., 2002).

\subsection{Modelling of the ontology of territorial knowledge domain}

According to the principles for modelling an ontology, it needs to the categorization of the object by descriptive knowledge in the domain. Identification of the concepts of the domain is key components of the ontology building. So, the concepts meaning should be normalized. The conceptualization step, in which the relations between concepts are captured, has to be detailed (Bachiment et al., 2002). Therefore, the methodology at this paper for modelling an ontology of territorial knowledge for sustainability according to the mentioned principles, at first, is the taxonomy of elements of territorial knowledge. The second step is the normalizing of these elements based on the foundational ontology of DOLCE which extracted their basic meaning. Finally, an ontology of domain as a DOTK is modelled.

\subsubsection{Elements of territorial knowledge for sustainability}

As mentioned, the first step for modelling a territorial ontology is extracting of elements of territorial knowledge which influence on the sustainability within industries. This taxonomy is done according to the literature review and four categories of geographical, human, economic, political capital and their 
sub-elements are identified. These four main categories of territorial knowledge consist of the tangible and intangible resources of territory for sustainability within industries. So, this knowledge can be represented by DOTK ontology.

Human capital is defined as ability, innovation ability and organization, individual skills, creativity, experience, ability to work in the team and learning (Francesconi et al., 2015). Intellectual capital (IC) as a taxonomy of human capital, is used to create and use knowledge to increase the industrial value. IC links to knowledge management in the organization of the industries through the knowledge and skills to improve the organizational process (Allais et al., 2013). Moreover, sharing of knowledge in network improve the learning process within industries and between actors (Jordao et al., 2017). In addition, individual and groups as stakeholders can be influenced by the organization and they need to the strategic help for sustainability in different industries' hierarchical level and their expectation should consider in decision making (Zhang et al., 2013). Innovation not sufficiently valued in strategic level of the industry because don't inform the strategic decision making that must be taken into account through knowledge management and governance in the company (Allais et al., 2017). Sharing of value for customers is created by the network that supports the design activity (Allais et al., 2015). Also, geographical information system (GIS) can help product designers to analyze the environmental impacts before and after design, which change design characteristics and product specifications based on the environmental status of each geography (Vadoudi et al., 2017).

The geographical capital is considered as action perimeter and is the based system including physical features of the earth, atmosphere, resource, infrastructure and socio-ecological activities (Dahlman et al., 2015). Geographical capital compartmentalizes into the environmental geography, ecosphere and infrastructure in this research. Environmental geography is the interaction of humanity and environment and defines as space for the circulation flow. Eco-sphere refers to human-environmental systems (Vadoudi et al., 2017). Infrastructures act as fundamental facilities to improve the productivity of existing resources technology. The natural resource, as sub-concepts of eco-sphere, is described all of the input flow from eco-sphere that enter to the techno-sphere (Zhang et al., 2015). Substance flow as a subset of a natural resource is considered a key factor to evaluate the resource consumption and environmental impacts. Substance flow can flow within the techno-sphere, and between techno-sphere and eco-sphere and their environmental impact should be taken into account by industries through product lifecycle in the geographical system. Techno-sphere refers to global technology system integrating all human activities (Vadoudi et al., 2017). Technology is another sub-cluster of infrastructure that enhances the productivity of industries and flexibility with the supplier (Allais et al., 2013).

Political capital is the only legitimate arena to define development guidelines and take precedence over economic actors and it must coordinate sustainable industrial strategies and expectations from civil society (Pecqueur, 2006). Governance principles as the main element of political capital, facilitate the coordination between political, territory and company sphere (Buclet, 2011). It must be adapted by integrating the multiplicity of stakeholders (individual and groups) and their expectation in taking decision compatible regarding existing rules (Allais et al., 2015). The principle of governance such as capability, democracy, council and administration in different scales (local, regional, national and international) support the industries for sustainable development. Capability improves the development of the capacity of organizations/individuals to meet their own expectation and decision-making level. It helps to top managers and giving the value to the initiatives at the strategic level that come from the operational level. Democracy aims to create a balance between individual preferences and the common interest in meeting the challenge of sustainable development in the company (Allais et al., 2017).

Economic sphere is defined as a means which enable the realization of the human capital objective with respect to the ecological boundaries (Allais et al., 2013). Economic capital creates the value for customers by use of an artefact and by optimizing production cost and strategic positioning in the value creation for industrial companies. The aim of the service economy is to create value by adding service to products. Value for the client in the service economy is created via the multiplicity of service associated with an inexpensive good by the company and for the company is created by the maintenance of the lowest production cost (Allais et al., 2015). The quaternary economy's goal is to create value for the clients by customizing the response to his specific request and for the company by tailoring a panel of products and services that meet client expectations. Mass consumption is the base of the market economy. The value for the clients is created by the possession of a rewarding object such as brand and for the company by the desirability of products and reduction of production costs 
(Debonneuil, 2007). The economy of functionality creates the value for the client by the satisfaction of a level performance supported by product- service pair (Allais et al., 2017).

\subsubsection{Foundational ontology for normalizing of the territorial knowledge domain}

Foundational ontologies are ontologies that: (i) have a large scope, (ii) can be highly reusable in different modelling scenarios, (iii) are conceptually well founded, and (iv) are semantically transparent (Borgo and Masolo, 2009). Also, foundation ontologies focus on the concepts (such as concepts of object, event, quality, role) and relations (such as constituency, participation, dependence), that are not specific to particular domains but can be suitably refined to match application requirements. They provide a starting point for building new ontologies (Oberle et al., 2007). So, foundational ontologies have the ability to provide conceptual handles to carry out a coherent and structured analysis of the domains. DOLCE (Descriptive Ontology for Linguistic and Cognitive Engineering) and SUMO (Suggested Upper Merged Ontology) are Two foundational ontologies. These ontologies are formed to reuse and extend for the particular domain to form an ontology of domain (Sevcenko, 2003) and they can help for normalizing of elements of territorial knowledge to model the DOTK ontology. Gangemi et al. (2003) show that foundational ontologies can act as a set of formal guideline for domain modelling, and as a tool for making heterogeneous ontologies interoperate and integrating heterogeneous knowledge coming from different sources. Therefore, it needs to select one of the foundational ontologies for normalizing.

\subsubsection{Comparison of DOLCE and SUMO ontology}

DOLCE ontology is a resource for designing knowledge system belong ontologies and formal description of the structure of knowledge bases. SUMO is another foundation ontology that organized into a single hierarchy rooted at the entity, representing the most general concepts. According to DOLCE, different entities can be co-located in the same space-time (Oberle et al., 2006). DOLCE is based on a fundamental distinction between enduring and perduring entities and abstract. Endurants can change in time such as physical objects while perdurants cannot change in this sense since none of their parts keeps its identity in time. Abstract includes both object-level concepts, such as set, time, space, and meta-level concepts such as attribute, relation and the entities of abstract exist neither in time nor in space (Gangemi et al., 2003). Entities in SUMO ontologies are divided physically existent stuff and mentally represented stuff (abstract) (Sevcenko, 2003). Table 1 shows a comparison between DOLCE and SUMO ontology. DOLCE has clear typical ontological choices in comparison with SUMO. For example, the multiplicative vs. reduction that allows different entities to co-localize in the same spacetime and using a modal logic coincides with possibilism vs. actualism (Oberle et al., 2006). Also, endurants correspond to 3D objects and perdurants correspond to 4D objects (Niles \& Pease, 2001). SUMO ontology is relatively low coverage that does not allow for open-domain applications (Sevcenko, 2003) while DOLCE ontology serves a drivers range of ontologies in different subject areas (Eisemann, 2009). So, DOLCE ontology can be used to normalize the territorial knowledge.

Table 1. Comparison of SUMO and DOLCE ontological choices (Oberle et al., 2006)

\begin{tabular}{|l|c|r|}
\hline & SUMO & DOLCE \\
\hline descriptive/ revisionist & $\begin{array}{c}\text { unclear(tends towards } \\
\text { description) }\end{array}$ & multiplicative \\
\hline $\begin{array}{l}\text { reductionist/ } \\
\text { multiplicative }\end{array}$ & $\begin{array}{c}\text { unclear( tends towards } \\
\text { multiplicativism) }\end{array}$ & possiblism \\
\hline actualism/ possibilism & $\begin{array}{c}\text { unclear(tends towards } \\
\text { actualism) }\end{array}$ & 3D/4D \\
\hline $\begin{array}{l}\text { endurantism (3D)/ } \\
\text { perdurantism (4D) }\end{array}$ & 3D & \\
\hline
\end{tabular}

\subsubsection{Descriptive Ontology for Territorial Knowledge (DOTK)}

DOLCE ontology can act as a formal guideline for domain modelling and it has the ability to provide conceptual handles to carry out a structured analysis of the domains (Gangemi et al., 2003). So, the normalizing of elements of territorial knowledge for sustainability is necessary. In other words, it needs to characterize the essentials which determine the objects that retain the studied domain. Thus, an ontological taxonomy is done according to the essence of notions of DOLCE ontology which are used their basic 
meaning. The meaning of notions is understood through their positions in the ontology. finally, a descriptive ontology for territorial knowledge (DOTK) is presented that it is explained about its entities in below.

Perdurants comprise what are variously called events, processes, phenomena, activities and states. Also, abstract seems to fit the latter group of terms such as attribute, relation, and possibly. Substantial and Quality are the two main categories of endurants. Qualities can be seen as the basic entities that it can be perceived or measured and they constantly dependent on the entity. Substantials are physical and nonphysical, according to whether they have entities with spatial qualities or not (Gangemi et al., 2003).

Characterizing the essentials of perdurants seek to identify the territorial knowledge as event, stative, phenomena, internal and intentional process, etc. In fact, it clarifies the essence of temporal parts or spatial parts. Most of the concepts of territorial knowledge are placed in stative as shown in figure 1.

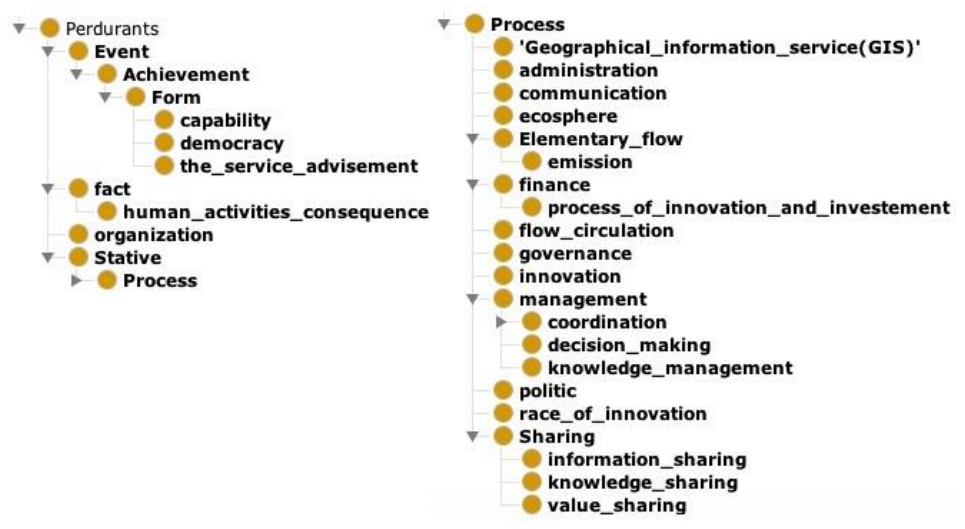

Figure 1. Hierarchy class of entities of perdurants of DOTK ontology

Some of the territorial knowledge concepts are adapted to the different essence of abstract entities. Some of the geographical, human, economic and political elements and their sub-class are characterized by abstract entities that demonstrated in figure 2 .

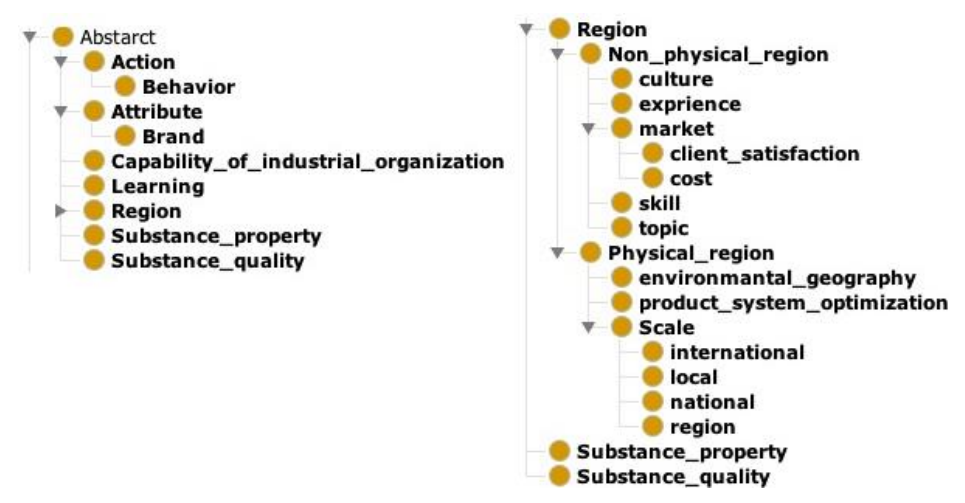

Figure 2. Entities of DOTK ontology in abstract

Endurants are wholly present at which they exist and mainly as a physical object. There are many concepts of territorial knowledge which are compatible with the essence of endurants entity. Especially, most of the sub-classes of geographical and human capitals are adapted with endurants as substantial and quality according to their essence. Moreover, some of the political and economic taxonomy are placed in substantial entities. These entities are shown in figure 3.

In summary, the descriptive ontology of territorial knowledge clarifies the essence of territorial knowledge for sustainability. This clarification is demonstrated by the position of each concept in DOTK. So, DOTK ontology act as a vocabulary that can consider the necessary semantics in order to establish information sharing from territorial knowledge. Moreover, DOTK ontology provides details about the essence and intention of territorial knowledge concepts which help the actors of industries. In addition, DOTK ontology is a domain ontology and it is a guide for the identification of resource of a specific territory. Entities of DOTK ontology lead to extract the knowledge of the special domain and its result is an applied ontology. So, in the following section, DOTK ontology is used to consider the concepts of a specific territory (Troyes city) for sustainability. 

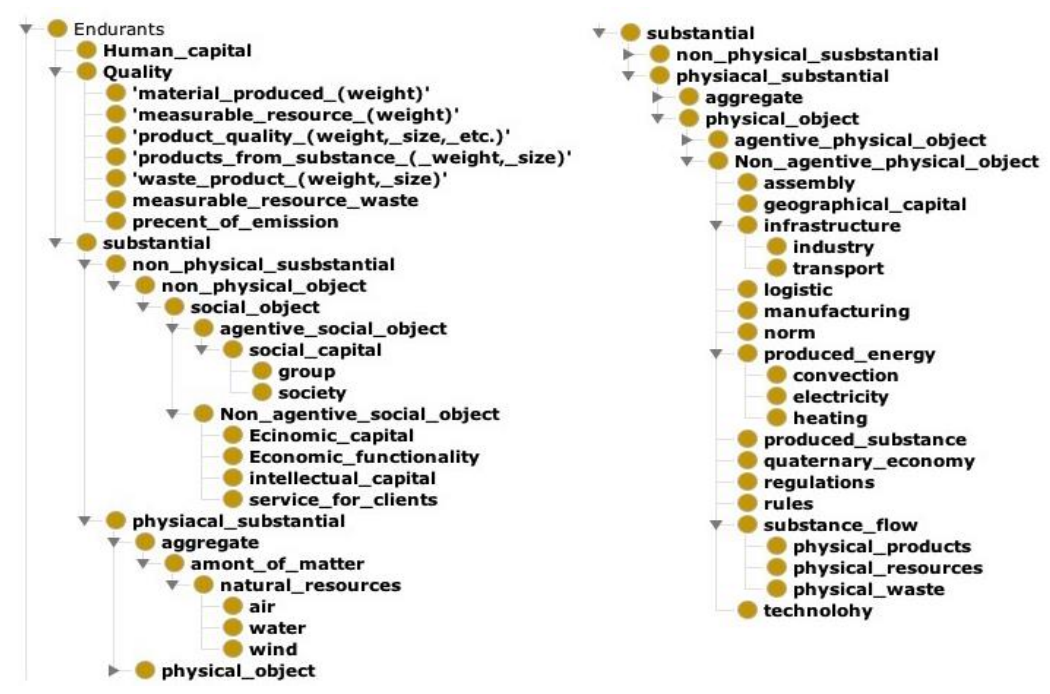

Figure 3. Entities of DOTK ontology in endurants

\section{IMPLEMENTATION OF DOTK ONTOLOGY IN THE TERRITORIAL RESOURCE OF TROYES}

DOTK ontology categorized the different concepts of territorial knowledge in abstract, perdurants and endurants entities for the goal of sustainability. DOTK ontology is considered the level of conceptualization of territorial resources for sustainability. At the level of conceptualization, DOTK ontology is a means to investigate knowledge and clarify the relationships between concepts. At the operational level, ontologies' main role is to allow a fluent dataflow between heterogeneous environments (Lemaignan et al., 2006). DOTK ontology is applied in the specific territory to guide the identification of knowledge. So, a new operational ontology is constructed by DOTK ontology. The aim is to prove and validate that DOTK ontology can help to extract the territorial resource of each geographical territory for some concepts of sustainable development to aid both companies and territory. Thus, each concept of DOTK ontology conduct to find the corresponded concepts for modelling of operational ontology. Thus, DOTK is applied to the Troyes. Troyes is capital of the department of Aube in north central of France and Textile companies' production are popular clothing brand as the economy of this city.

This Ontology presents the entities of territorial resources (tangible and intangible) of Troyes according to their essence and meaning. The entities of this ontology can help the industries toward sustainability by presenting the tangible and intangible resources located in the territory of Troyes. The methodology for extracting of these concepts is the searching on the internet which is corresponded to the Troyes's territorial resources according to the DOTK concept. Figure 4 demonstrates the abstract concepts of DOTK ontology of Troyes such as learning, skill, brand, client satisfaction, product system optimization and environmental geographical concepts that can aide the industries and territory. As an instance, the environmental club of Troyes informs and discuss the environment and sustainable development issues in companies which is sub concept of environmental geography. Moreover, physical impact on the environment such as safety and conservation of the quality of soil, decreasing the influence on the natural environment, reducing the influence on the human environment such as security and health are some main concepts which are considered in the environmental geography of Troyes. Product service optimization is conducted this collective operation via CCI Troyes whose goal is the optimization of the logistics of companies, both in the management of production operations (supply chain) and for the vehicle tour (collection or delivery) relying on the skills of Laboratory of Optimization of Industrial Systems(LOSI) at University of technology of Troyes. Rés'Aube Compétences is a network of economic and social players which one of the common objectives is to connect employers and assets. These structures are intended to enrich the skills and performance of companies, associations and local communities. Thus, these abstract concepts of DOTK ontology of Troyes can help the hierarchical level of industries to integrate these concepts as a territorial knowledge to their activities for sustainability. So, this research is continued to identify other concepts of endurants and perdurants of DOTK of Troyes. 


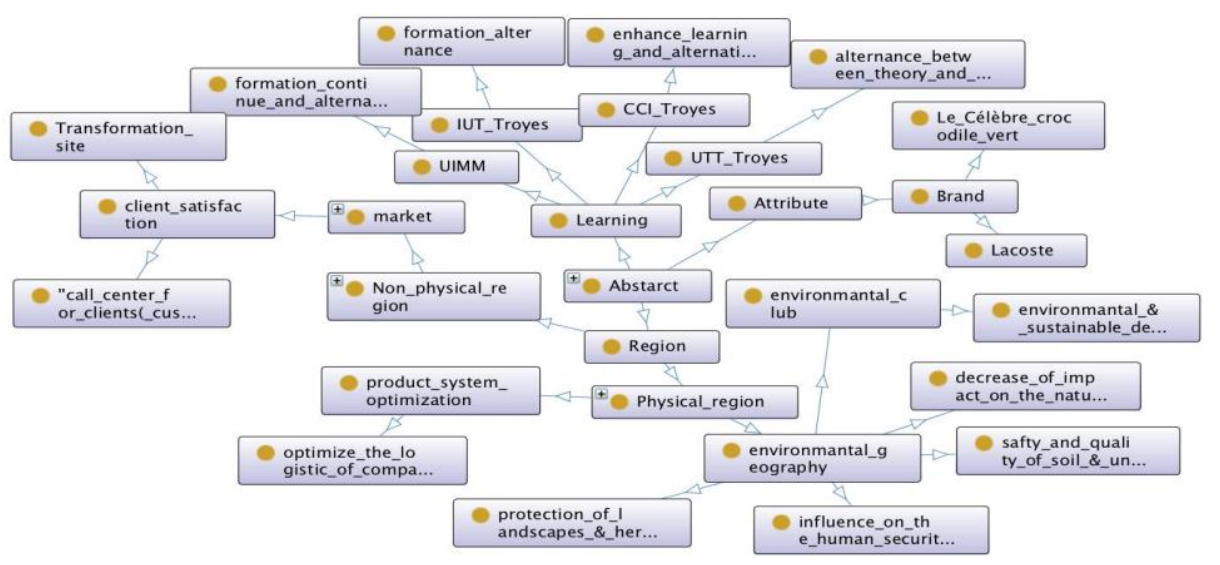

Figure 4. Abstract concepts of DOTK ontology of Troyes

Searching about the political capital of Troyes as a process of perdurants show that one of the main goals is economic activities from local employment in the different section such as agriculture, human health, social action and non-agricultural market sectors. Moreover, wealth creation is another politic that gains from work factor and capital factor, natural resources of Troyes. Work factor consists of human activities (intellectual or manual) and capital factors which divided into circulating technical capital and fixed technical capital. Reduction of the environmental impact such as energy consumption, rubbish production, climate change and etc. is another politic that it is followed in this commune. Social in corporate governance is provided companies with the answer to the concepts and challenges of sustainable development by the corporate social responsibility of CCI of Troyes. It helps the companies for social relation within companies, health, safety, policies implemented in training and organization of work. Organizing of training is one of the main issues in the organizational level of industries of this commune. These elements can improve sustainability in companies from social aspects. Moreover, environmental aspects in corporate governance and sustainable development issue inform and discuss in companies by the environmental club of Troyes. The University of Technology of Troyes, technopole of Aube and park of technology and scientific activities have the cooperation with industries to innovate. Also, the club of industrial ecology of Aube acts as a network of exchange of information for industrial ecology between industries to share the information of this domain. Figure 5 shows the concepts of perdurants of DOTK ontology of Troyes.

Most of the concepts of endurants of DOTK ontology of Troyes are located in the Non-agentive physical object of substantial entities which can help the industries. Regulation, energy product, infrastructure, physical waste and logistic are main concepts. Two main energy productions are electricity and heating energy produces through water circuit a biomass boiler room. This pure energy can help the environment. Also, developing renewable energy, development of recycling sector and environmental issue awareness are some of the regulation which helps both industries and territory's ecology.

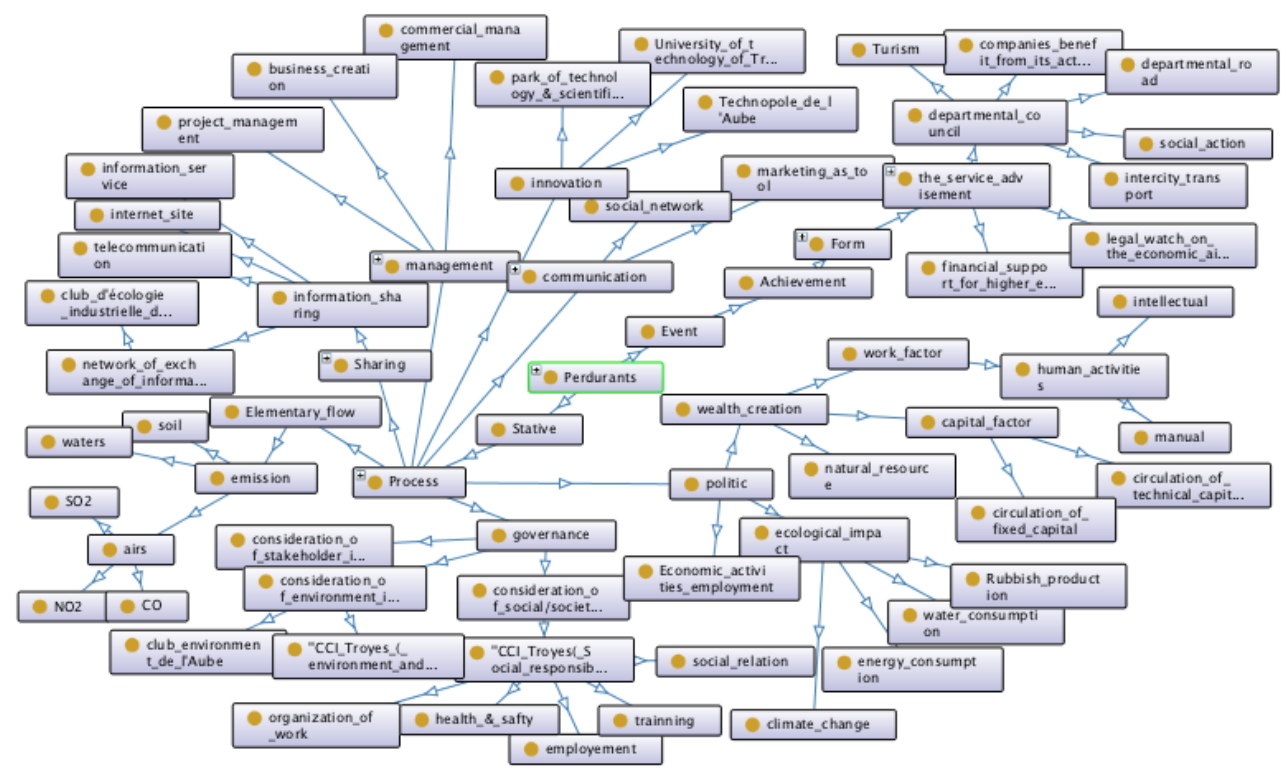

Figure 5. Perdurants concepts of DOTK ontology of Troyes 
Industries of Troyes produce the textile, metal products, rubber, plastic, paper and transport equipment. Park logistic help to industries for reshipment of products, storage through the transport by railroad and land transport. Also, the supplier provides the products and raw material for the industries that they need for their project or production. In addition, the natural resource such as wind, water, forest and woods, fossil energy provide the resources for industry and territory of Troyes. The central heating network and disposal of non-hazardous waste are the main technology in Troyes that assist this geographical territory. Another concept of this ontology for economic functionality is Xerox corporation which sells the print and digital document. This corporation realizes economic functionality based on an integrated management strategy for its products, combined with an offer to sell to its customers and service of satisfaction of their needs. There are other concepts that DOTK ontology guide to identify them from the resources of Troyes. Figure 6 demonstrates other territorial resources of Troyes as endurants that extracted by implementing DOTK ontology. So, apply the concepts of DOTK in this real case allow to find the territorial resources which can be useful for hierarchical levels of the company and also, for the territory. In addition, there are some concepts in the DOTK ontology that there have not corresponded concepts for them in Troyes. So, it shows the lack of resources of Troyes which are identified by DOTK ontology and Troyes city should develop these resources for responding to sustainability.

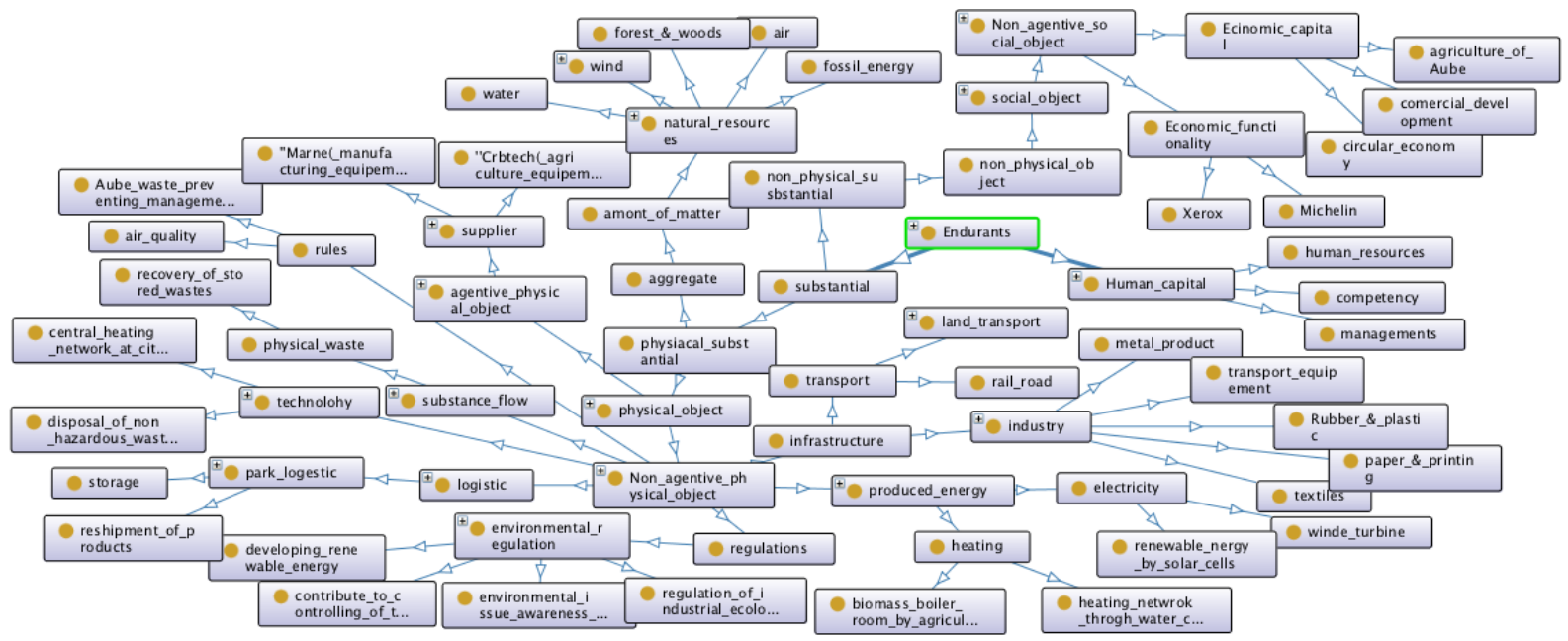

Figure 6. Endurants concepts of DOTK ontology of Troyes

\section{CONCLUSION}

This paper state the lack of territorial knowledge as a barrier for searching the useful concepts of sustainability within industries. Moreover, sustainability should be integrated into activities of industries to understand the relation of concepts of territory in local scale. It is founded that ontology is a useful method that makes the assumptions explicit. So, firstly, analysis of territorial knowledge for sustainability within industries is done to create a taxonomy of elements. Then, normalizing of these elements by the foundational ontology of DOLCE is implemented. Finally, the descriptive ontology for territorial knowledge (DOTK) is proposed which extracts the essence of notions and their meaning. DOTK ontology represents the "why reasoning" of each entity of territorial knowledge to help the comprehension of these entities. The elements of territorial knowledge in DOTK ontology is extracted from the literature review for sustainability. Then, DOTK ontology is applied in the real case. This implementation is justified which DOTK ontology act as a guide to identify the resources of a specific territory for industries. This applicable ontology can help to the hierarchical levels of industries of this city to know about available resources of its territory. Moreover, one of the properties of DOTK ontology is that it can be used for identifying the resources of each territory to help the industries. In future work of this ongoing research, a semantic graph of DOTK of Troyes is proposed to help the comprehension of the semantic relationship between concepts. Moreover, the interview with experts of industries will be done. The goal of the interview is to investigate which concepts of DOTK ontology of Troyes are considered in their activities and how these concepts can help them for the sustainability. 


\section{REFERENCES}

Allais, R., Roucoules, L. and Reyes, T. (2017), “Governance maturity grid: a transition method for integrating sustainability into companies?”, Journal of cleaner production, Vol. 140, pp. 213-226. https://doi.org/10.1016/j.jclepro.2016.02.069.

Allais, R., Roucoules, L. and Reyes, T. (2015), "Inclusion of territorial resources in the product development process", Journal of cleaner production, Vol. 94, pp. 187-197. https://doi.org/10.1016/j.jclepro.2015.01.091.

Allais, R., Reyes, T. and Roucoules, L. (2013), "Exploratory study of the inclusion of territorial resources in design process", ICED2013, pp. 10.

Bachimont, B., Isaac, A. and Troncy, R. (2002, October), "Semantic commitment for designing ontologies: a proposal”, International Conference on Knowledge Engineering and Knowledge Management, Heidelberg, Springer, Berlin, pp. 114-121. https://doi.org/10.1007/3-540-45810-7_14.

Bachimont, B. (2000), "Engagement sémantique et engagement ontologique: conception et réalisation d'ontologies en ingénierie des connaissances", Ingénierie des connaissances: évolutions récentes et nouveaux défis, pp. 305-323.

Borgo, S. and Masolo, C. (2009), "Foundational choices in DOLCE”, Handbook on ontologies, Heidelberg, Springer, Berlin, pp. 361-381. https://doi.org/10.1007/978-3-540-92673-3_16.

Brachman, R.J., McGuinness, D.L., Patel-Schneider, P.F., Resnick, L.A. and Borgida, A. (1991), "Living with CLASSIC: When and how to use a KL-ONE-like language", Principles of semantic networks, pp. 401456. https://doi.org/10.1016/b978-1-4832-0771-1.50022-9.

Bouaud, J., Bachimont, B., Charlet, J. and Zweigenbaum, P. (1995, August), "Methodological principles for structuring an "ontology"”, Proceedings of the IJCAI'95 Workshop on "Basic Ontological Issues in Knowledge Sharing, pp. 19-25.

Buclet, N. (2011), “Territoire, innovation et développement durable: l'émergence d'un nouveau régime conventionnel?", Revue d'Économie régionale \& urbaine No. 5, pp. 911-940. https://doi.org/10.3917/reru.115.0911.

Dahlman, C.T., Renwick, W.H. and Bergman, E. (2015), Introduction to Geography: People, places \& environment, Pearson.

Debonneuil, M. (2007), L'espoir économique: vers la révolution du quaternaire, Bourin éd.

Fensel, D. (2001), Ontologies, pp. 11-18. https://doi.org/10.1007/978-3-662-04396-7_2.

Figuière, C. and Rocca, M. (2008, November), "Un développement véritablement durable: quelle compatibilité avec le capitalisme financier?", Colloque international" La problématique du développement durable vingt ans après: nouvelles lectures théoriques, innovations méthodologiques et domaines d'extension", CLERSE, Lille, 20-22 novembre 2008. https://doi.org/10.4000/developpementdurable.8641.

Francesconi, A. (2015), "The Territory as a Reference Key”, Advanced Cultural Districts, Palgrave Pivot, London, pp. 54-73. https://doi.org/10.1057/9781137555359_3.

Gangemi, A., Guarino, N., Masolo, C. and Oltramari, A. (2003), "Sweetening wordnet with dolce", AI magazine, Vol. 24 No. 3, pp. 13. https://doi.org/10.1007/3-540-45810-7_18.

Gruber, T.R. (1993), “A translation approach to portable ontology specification”, Knowledge acquisition, Vol. 5 No. 2, pp. 199-220. http://doi.org/10.1006/knac.1993.1008.

Hallstedt, S., Ny, H., Robèrt, K.H. and Broman, G. (2010), “An approach to assessing sustainability integration in strategic decision systems for product development”, Journal of Cleaner Production, Vol. 18 No. 8, pp. 703-712. http://dx.doi.org/10.1016/j.jclepro.2009.12.017.

Jordão, R.V.D. and Novas, J.C. (2017), "Knowledge management and intellectual capital in networks of smalland medium-sized enterprises", Journal of Intellectual Capital, Vol. 18 No. 3, pp. 667-692. https://doi.org/10.1108/jic-11-2016-0120.

Oberle, D., Ankolekar, A., Hitzler, P., Cimiano, P., Sintek, M., Kiesel, M., Mougouie, B., Baumann, S., Vembu, S., Romanelli, M. and Buitelaar, P. (2007), "DOLCE ergo SUMO: On foundational and domain models in the SmartWeb Integrated Ontology (SWIntO)", Web Semantics: Science, Services and Agents on the World Wide Web, Vol. 5 No. 3, pp. 156-174. https://doi.org/10.1016/j.websem.2007.06.002.

Pecqueur, B. (2006), “Le tournant territorial de l'économie globale”, Espaces et sociétés No. 1, pp. 17-32. https://doi.org/10.3917/esp.124.0017.

Ševcenko, M. (2003), “Online presentation of an upper ontology”, Proc. of Znalosti 2003.

Vadoudi, K., Bratec, F. and Troussier, N. (2017), "A GIS-oriented semantic data model to support PLM for DfS”, International Journal of Product Lifecycle Management, Vol. 10 No. 3, pp. 210-230. https://doi.org/10.1504/ijplm.2017.10008304.

Zhang, F., Rio, M., Allais, R., Zwolinski, P., Carrillo, T.R., Roucoules, L., Mercier-Laurent, E. and Buclet, N. (2013), "Toward an systemic navigation framework to integrate sustainable development into the company", Journal of cleaner production, Vol. 54, pp. 199-214. https://doi.org/10.1016/j.jclepro.2013.03.054.

Zhang, Y., Luo, X., Buis, J.J. and Sutherland, J.W. (2015), "LCA-oriented semantic representation for the product life cycle", Journal of Cleaner Production, Vol. 86, pp. 146-162. https://doi.org/10.1016/j.jclepro.2014.08.053. 